\title{
AN EXPLORATORY STUDY OF AFFECTING KEY FACTORS ON MARKET ORIENTATION BY SMALL AND MEDIUM SCALE ENTERPRISES
}

\author{
Gunawardana T.S.L.W and Jayampathi E.K \\ Faculty of Management and Finance, University of Ruhuna, Matara, Sri Lanka \\ gunawardana@badm.ruh.ac.lk, jayampathi2k@gmail.com
}

\begin{abstract}
Small and Medium scale Enterprises (SMEs) are called as the engine of the economy in developing countries such as Sri Lanka. Accordingly, SMEs are playing significant role in socio economic development of any country. In Sri Lanka, SMEs are contributed for the national GDP by 70\% (Central Bank of Sri Lanka, 2013). Majority of SMEs are being engaged with local resources utilized business activities. SME creates a platform for locals to manufacture products and services using indigenous resources to get its optimum contribution for the nation. Majority of SME entrepreneurs are doing their own enterprises utilizing their own skills, knowledge, and expertise and so on. They are much creative enough in developing new product and service concepts in order to the market standards. How much standards they are following on, marketing their products and services is the main obstacle they have confronted. Due to poor market orientation practices followed by SMEs, still they cannot produce their maximum contribution to the economy. Having an intention on these obstacles confronted by SMEs, this study is designed to identify the key determinants affecting on market orientation by SMEs. Further this study attempted into identification of issues and barriers that are inhibited the producing market oriented products and services by SMEs. For the purpose of this field study researches have selected Matara District as their research site. Small and Medium scale entrepreneurs were the population for this study. Numbers of 50 SMEs have been randomly selected for the sample and a structured questionnaire was used to gather relevant primary data. Using factor analysis technique results were found. The results were discussed relating to four key areas; market based rewards systems, top management emphasis, inter-functional connectedness and management risk posture. Finally the study concluded that designing the cushion environment for SMEs is the responsibility of policy making bodies to get the maximum of SMEs within this challenging economic conditions and hostile competitive environment.
\end{abstract}

Keywords: Challenges and Issues, Market orientation, Small and Medium scale Enterprises (SMEs) 


\section{INTRODUCTION}

The exploratory work conducted prior to this study work also pointed to the importance of being dedicated towards customers, scholarly contributions on the marketorientation became very interesting. As Kara et al. (2005) explain, several research findings indicating key factors affecting market orientation highlights the significance of market orientation. Through the review of scholarly contributions on the market orientation, it was discovered that the innovation and entrepreneurship research fields could provide valuable input to the research model. In fact, researchers examining the key factors affecting on market orientation have increasingly added innovation, and innovativeness as constructs to their research models (Slater and Narver 2000; Agrawal et al.2003), and the research findings indicate that such constructs provide new insight to the concept of market orientation. Complementing market orientation by entrepreneurship and innovation was in fact the basic idea presented by Peter Drucker as early as in 1954. He defined a business purpose to create a customer, and stated that "because it is its purpose to create a customer, any business enterprise has two and only these two basic functions: marketing and innovation".

The ornamental fish market in Sri Lanka is one of the significant sectors in Sri Lankan economy. The small and medium scale ornamental fish entrepreneurs in the
Southern Sri Lanka contribute a lot to the sectorial development through facilitating contract basis supplies. As such, it is interested in understanding more about the key factors driving the market orientation of small and medium scale entrepreneurs in the ornamental fish industry, Sri Lanka. The research question leading a direction to an empirical investigation in this study is 'what are the key factors affecting on market orientation of small and medium scale enterprises (SMES)?

\subsection{Significance of the study}

The review of literature conducted as part of this study confirms the existence of relatively few empirical studies focused on the market orientation with respect to small and medium scale business (Aldrich 1990; Herron and Robinson 1993). In fact, researchers have commented upon the large extent of exploratory and qualitative research that now exists on business, and that this research is mixed in quality and academic rigour (Robinson 1998; Sandberg and Hofer 1987). The current research is as such a response to the urge for more empirical studies within this novel research area in terms of surveys. It thereby adds to the existing body of literature, and provides several insights for managers in livestock firms.

This research also contributes to the ongoing effort within entrepreneurship research to develop valid and reliable scales. Market orientation is still a novel research area where researchers face measurement 
challenges due to the lack of sophisticated measures. Researchers have therefore urged for the development of better means for measuring new aspects in terms of construct and instrumentation development (Vesper 1990; Westhead et al. 2001). The market orientation scale developed in the current study provides such a means, and gives researchers a rigorous research procedure that may relive them from repeated efforts at construct and instrumentation development when it comes to the small and medium scale enterprises.

\section{LITERATURE REVIEW}

This section is fully devoted to present previous research findings and relevant literature from various research fields to enrich the selected concepts of the study. Together with observational data collected data prior to this study, the review of prior theory from the different research fields, and findings reported in relevant empirical surveys, justified the inclusion of market orientation as the main variables in the research model.

\subsection{Market orientation}

Marketing academicians and marketing managers have over decades been claiming that firms increasing their market orientation will improve their market performance (Narver and Slater 1990). Furthermore, market orientation is by many scholars regarded as one of the most important concepts in the marketing discipline (Kara et al. 2005). However, it was not until the beginning of the 1990s that systematic research on market orientation, and the consequences of a market orientation, really took off. This new stream of research treats market orientation as synonymous with implementation of the marketing concepts (Deng and Dart 1994). Slater and Narver (1994) are even more explicit when they describe implementation of the marketing concept as the firm's intentions to deliver superior value to its customers on a continuous basis by satisfying their wants and needs. The importance of a customer focus is emphasized by Desphande et al. (1993) who, in line with Drucker (1954), argue that the marketing concept calls for customer orientation and innovation as the focus for all business planning and strategy. Peterson (1989) regards the marketing concept as a business philosophy which requires that all employees focus their efforts on customer satisfaction, and that financial outcomes are results of the firm selectively meeting customer needs. In line with the aforementioned facts, most of researches have concluded that high market oriented companies perform better than companies that are less market oriented. They focus on adapting their products and services to the needs and expectations of their customers instead of those who are product oriented and focus on developing a product or service that is then marketed and hopefully sold. To achieve this customer focus, a firm with a high degree of market orientation cultivates a set of shared values and beliefs about putting the customer first 
and reaps results in form of a defendable competitive advantage, decreased costs and increased profits.

Nevertheless, before reviewing the research on the market orientation construct and the different market orientation perspectives, it may be worth-while to briefly discuss the philosophy behind the marketing concept as it has developed during the years. As Day (1994) argues, business managers have over the last 50 years been advised to stay close to the customer, to put the customer at the top of the organization chart, and to define the purpose of the business as the creation and retention of satisfied customers. Since, Drucker (1954) argued that creating a satisfied customer was the only valid definition of business purpose, there have been many subsequent authors describing the marketing concepts and its benefits (Day 1994).

Both Webster (1994) and Kotler and Amstrong (2006) emphasize that knowledge about customers, their characteristics, needs, and preferences are the core of the marketing concept. Knowledge, understanding, and commitment are also shared throughout the organization in the marketing concept. As Webster (1994: 28) puts it, in implementing the marketing concept "marketing becomes the part of the organization's culture as well as knowledge systems that guide decision making at all levels". Hence, all decision making in market-driven firms centers round customer information, competitive intelligence, and a clear concept of the firm's value proposition (Webster 1994). This is consistent with arguments made by Gronroos (1999) and Gummesson (1991), who argue that the entire organization should be responsible for the marketing function. The discussion above, and also consistent with the historical examination by Wrenn (1997), indicates that the marketing concept generally has been conceded to consist of three elements: 1) customer philosophy 2) goal attainment, and 3) integrated marketing orientation. The third element relates to an organization-wide effort to satisfy corporate goals by satisfying customer needs and wants.

Market orientation scholars such as Kohli and Jaworski (1990), Narver and Slater (1990), Ruekert (1992), Gainer and Pandanyi (2005), and Carr and Lopez (2007) have argued that market orientation traces its origins from the market concept and has consequences to overall business strategy. The marketing concept is concerned with customer orientation, competition orientation, innovation and profit as an inducement for creating satisfied customers (Narver and Slater, 1994; Hunt and Morgan, 1995).

Although there are many perspectives in marketing concepts, in this study consider about customer orientation, competitor orientation, inter-functional coordination and social benefit orientation. Market orientation has been widely accepted by scholars as the implementation of the market 
concept, as an organizational culture, or as a mix of those two (Greenley, 1995; Han, Kom and Srivastave, 1998). Other scholars argued that market oriented behaviour in marketing new solutions leads to better performance, has positive effects on customer satisfaction and loyalty as well as innovation, employee satisfaction and cooperation (Twaites and Lynch, 1992, Deshpandé, Farely and Webster, 1993; Gatignon and Xuereb, 1997).

\subsubsection{Customer Orientation}

The modern marketing concept is well described and discussed by Kotler and Amstrong (2006). The objective underlying the modern marketing concept is to develop a customer relationship in which the sale is only the beginning (Webster 1994). This is consistent with the notion Kotler and Amstrong (2006) make, that the marketing concept is a kind of consumer-centered "sense and respond" philosophy. As such, Kotler and Amstrong (2006: 10) define the marketing concept as "the marketing philosophy that holds that achieving organizational goals depends on knowing the needs and wants of target markets and delivering the desired satisfactions better than competitors do". Hence, under the modern marketing concept, customer focus and value are of utmost importance for sales and profit. As Webster (1994: 22) states, "to survive in the future, every business will have to be customer focused, marketdriven... and flexible in its ability to deliver superior value to customers whose preferences and expectations change continuously". According to Webster (1994), it is the value delivery concept of strategy that has helped bring customer orientation, as called for by the old marketing concept, back into the forefront. He further states that in the new marketing concept the focus is sharpened by adding the idea of the value proposition, or what Kotler and Amstrong (2006) define as "a set of benefits that they (companies) promise to customers to satisfy their needs".

Narver and Slater (1990) described customer orientation as the sufficient understanding of a company's target customers to be able to create superior value for them continuously. It requires that marketers understand a buyer's entire value chain (Day and Wensley, 1988). This dimension has received a good deal of attention in the research literature (Deng and Dart, 1994).Kohli and Jaworski (1990) found in their interviews with company managers that a customer focus is a critical element in determining market orientation.

\subsubsection{Competitor Orientation}

A competitor orientation may lead to a cost advantage because competitor oriented businesses tend to watch costs closely, so they may quickly match the marketing initiatives of competitors. According to Narver and Slater (1990, p. 21-22) competitor orientation, as an element of market orientation, means that "a seller understands the short-term strengths and weaknesses and long term capabilities and 
strategies of both the key current and potential competitors". The purpose of a competitor orientation is to provide a solid basis of intelligence pertaining to present and potential competitors for executive actions. Competitors can be defined as firms offering products or services that are close substitutes, in the sense that they serve the same customer need (Porter, 1980; Kotler, 2000). For example, in serving the coffee sweetener market, a provider of beet sugar faces competition from other providers of beet sugar, as well as from providers of cane sugar and synthetic sugar. However, small organisations seem to view competitor orientation differently and are not as concerned with long term strategies. The literature suggests that most businesses are short-term oriented (Carson 1990, Harris and Watkins 1998), and that short-term results are perceived to be more important than long term strategic issues (Harris and Watkins 1998).

\subsubsection{Inter Functional Coordination}

Inter functional coordination describes the ability of different functional areas to accommodate disparate views and work around conflicting perspectives and mental models by putting aside functional interests for the better of the organization as a whole. As the literature on internal marketing is rapidly growing, Inter Functional Coordination is also viewed as an important criterion of internal marketing. Rafiq \& Ahmed (1993, p. 229) defined the boundary between marketing and human resources management while arguing that organizations need to "look at ways of increasing cross functional coordination". Though mentioned as early as in 1993, Inter Functional Coordination was not "officially" identified as one of the criteria of internal marketing until in 1993, when Rafiq \& Ahmed proposed a comprehensive definition of internal marketing. Rafiq \& Ahmed (1993) reviewed conceptual and empirical literature on the definition of internal marketing and identified Inter Functional Coordination as one of the five main criteria of internal marketing. Another way, Inter functional coordination is defined as the integration and collaboration of various functional areas (or departments) within an organization as a way of enhancing communication and information to better meet the organization's goal (Narver \& Slater, 1990). According to above definition to become customer oriented organization communication of information is must. Inter functional coordination describes the ability of different functional areas to accommodate disparate views and work around conflicting perspectives and mental models by putting aside functional interests for the better of the organization as a whole. Nakata and Sivakumar (2001) highlighted that inter functional coordination represent a key form of internal social capital of an organization. Organizational resources often have conflicting priorities, different perspectives, and strategies (Nakata and Sivakumar, 2001). Academics and practitioners have long contended that synergy among 
company members is needed. A culture of integrating all departments towards better and continuous creation of customer value should lead to a market orientation within the company and successful implementation of the marketing concept (Harrison and Shaw, 2004).

\subsubsection{Social Benefits Orientation}

Social benefits can be defined as the increase in the welfare of a society that is derived from a particular course of action. Most social benefits cannot be quantified (Adler, 2002). When considering this definition it is crystal clear that social benefit orientation is attach with the welfare of the customers or the society and each and every business organization should pay high consideration to the social benefits. It comes with the concept of corporate social responsibility. Furthermore, according to Adler (2002), social benefit is the total benefit to society from producing or consuming a good or service. Social benefits include all the private benefits plus any external benefits of production or consumption. Although in this definition they highlighted that Private benefit is a part of social benefit this study concern about the external benefits provided by the organizations. If a good or service has significant external benefits, then the social benefit will be greater than the private benefit. The social benefit achieved by a social project can be defined as the improvements attained in the living conditions of its beneficiaries that are directly attributable to the project. Another way of explaining about social benefit is defined by measurement against a "thirdparty standard," and all statutes permit incorporators to also pursue more "specific social benefits". Based on above perspectives importance of social benefit oriented activities has been increased. Most of the organizations are aimed to use strategies in order to positioning in consumer's mind about the organizations as well as the products.

\section{STUDY DESIGN AND METHODS}

Easter by Smith et al. (2001) categorize the philosophical positions or paradigms into two main traditions, phenomenology and positivism, and point out that each of the philosophical positions has implications for the choices to be made in the research design. The key idea of positivism is that the social world exists externally, and that its properties can be measured through objective methods. The current research is conducted largely from the positivist's paradigm. It is systematic, controlled and empirical, and the variables and constructs that are investigated are all operationalist and measured quantitatively. Furthermore, the research involves testing of hypotheses on a relatively large sample of firms where theory plays an important part in providing a systematic view of the relations that are studied.

\subsection{Pre-study}

A pre-study was conducted in order to 
investigate the small and medium scale business setting and to determine the relevant issues in selected key variable of the study. Seven interviews with the small and medium scale entrepreneurs and two interviews with the business consultants were organized. Two ready-made garment factory owners and one fabric painter were also interviewed. The pre-study particularly focused on the market orientation in their businesses. The researchers also had informal discussions with one of the directors of the small enterprise development division, Southern Province, One of the regional managers of the Sanasa Development Bank/ Southern province, and the Chairmen of the Chamber of Commerce/ Southern Province. Evidence from these interviews and informal discussions enriched the selected concept in the present study.

\subsection{The Sample, Study Variables, Questionnaire Design and Data Collection}

This study focuses on examining the key factors affecting on market orientation of small and medium scale ornamental fish farmers in Southern province, Sri Lanka. It was ensured to include respondents representing the entire province as well. Initially, 150 questionnaires were posted to randomly chosen small and medium scale ornamental fish farmers in the Southern Province Sri Lanka. However, only 20 respondents returned completed questionnaires. The response rate was very low (13\%). Next, it was decided to contact other small and medium scale entrepreneurs through telephone calls to get an appointment for personal interviews. Accordingly, another 130 respondents were contacted through telephone calls and 85 small and medium scale ornamental fish farmers agreed for interviews. However, only 100 questionnaires (out of 105 questionnaires) were usable to the survey as there were five incomplete questionnaires. A structured questionnaire was used in the study consisted of three parts i.e. background information of entrepreneurs, and market orientation. The data collection took place during November 2015 and December 2015.

The four study constructs of the study i.e. customer orientation, competitor orientation, inter functional coordination and social benefit orientation were operationalized as multi-item constructs. The variables of the customer orientation, competitor orientation and inter functional coordination were adopted from Narver and Slater (1990); Day and Wensley, (1988) and Langerak, et al. (2004). The variables of the social benefit orientation were adopted from Katz and Page (2010). Altogether twenty nine items (i.e., seven items for customer orientation, eight items for competitor orientation, seven items for inter functional coordination and seven items for social benefit orientation) were used to measure market orientation. All the variables were addressed by using a five point Likert Scale ranging from " $1=$ strongly disagree" to " $5=$ strongly agree".
Issue I - 2016 


\section{DATA ANALYSIS AND RESULTS}

Exploratory Factor Analysis tested whether the hypothesized number of factors underlies the data. CFA provides overall goodness-of-fit tests of the match between the theoretical factor structure and the data (Kahn, 2006) and tests the appropriateness of a hypothesized model (Heeler et al, 1977). Maximum Likelihood (ML) method was used since it is the most popular method to find parameter estimates that if they were the true population values would maximize the likelihood that the observed covariance matrix was drawn from that population (Kahn, 2006).

Chi Square statistic $\left(X^{2}\right)$ with the ratio of chisquare to degrees of freedom $\left(x^{2} / d f\right)$ was used to examine how close the observed variance-covariance matrix is to the estimated matrix of the proposed model. Comparative Fit Index (CFI), Normed Fit Index (NFI) and Tucker Lewis Index (TLI) were used to estimate the improvement in fit in the proposed model on the relationship between $\mathrm{MO}$ and $\mathrm{EO}$ on organizational performance. Parsimony of the model is examined with Root Mean Square Error of Approximation (RMSEA) index. The cutoff values close to 0.95 for TLI and CFI; cutoff value close to 0.06 for RMSEA can be used to conclude that there is a relatively good fit between hypnotized model and the observed data (Hu and Bentler 1999). Table 1 presents the measurements items and the results of the measurement model, including standardized factor loadings and composite Journal of Business Studies reliabilities..

The factor loadings of the latent variables are high and statistically significant.

\subsection{Table: Confirmatory Factor}

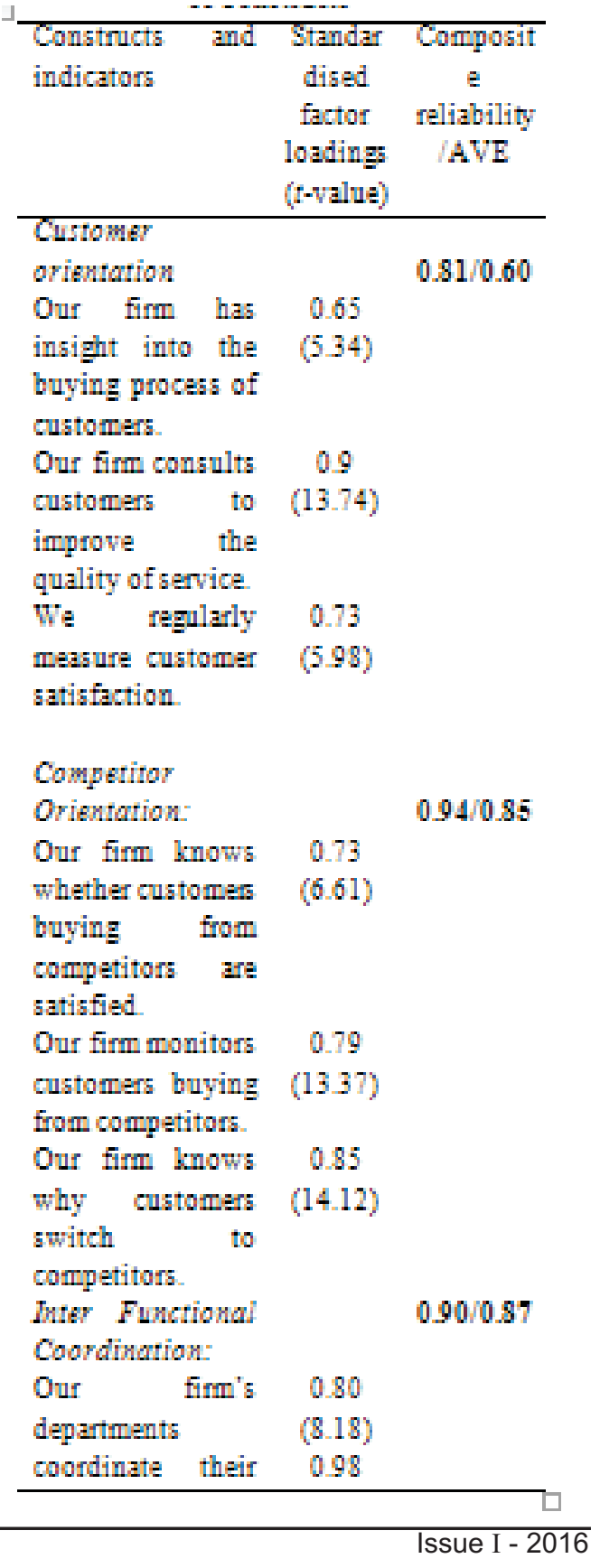




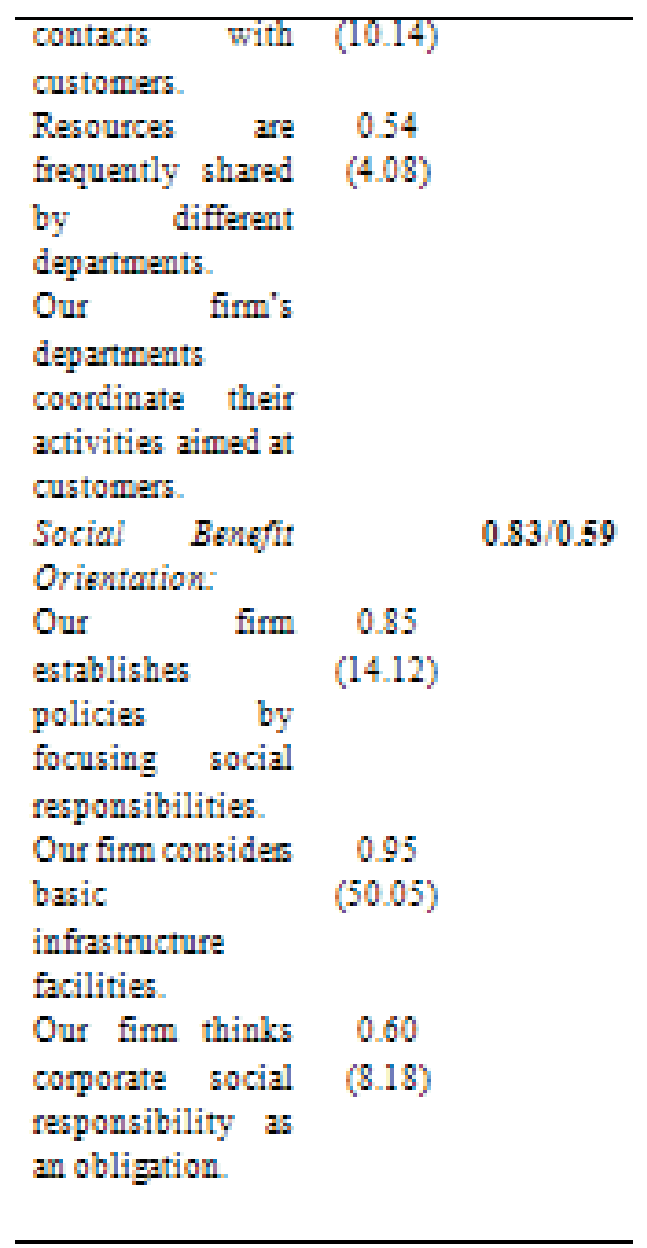

\section{Analysis of Constructs}

This Table 4.1 shows that the final confirmatory factor analysis (Measurement Model). After deleting items less loading values (criteria less than 0.5 suggested by Bagozzi and Yi, 1988) the fit of the respecified model improved to $\mathrm{X}^{2}=431.67$ with degree of freedom $=10$. Three different measures of internal consistency or reliability were computed and two are presented in table 3. First, all composite reliabilities are .7 or higher, which indicates that internal consistency among the measures far above the recommended level of .60 (Bagozzi and Yi, 1988). Second, average variance extracted ranged from 0.59 to 0.87 . Bagozzi and Yi (1988) suggested a target level is more than 0.50 .

\section{D I S C U S S I O N A N D CONCLUSION}

The aim of this study was to investigate the key factors affecting on market orientation (MO) and to examine how the dimensions of these constructs are related with a small and medium scale ornamental fish famers. Furthermore, relevant literature was reviewed in a systematically and determined manner. A review of relevant literature gave conceptual and empirical support for emphasizing the market orientation and its antecedents in small and medium scale businesses. The review of market orientation gave compelling reasons for continuing the search for relevant literature in the marketing research field and market orientation research in particular. Since the exploratory work conducted prior to the study also pointed to the importance of being dedicated toward customers, competitors, inter functional coordination and social benefit orientation scholarly contributions on the market orientation became very interesting and led to the inclusion of market orientation in the research model. Furthermore, the review of the research literature on the market orientation made it evident that the innovation and 
entrepreneurship research fields could provide valuable input to the research model for this research. An emphasis was put on empirical studies reported in the corporate entrepreneurship research field, and in particular studies aimed at clarifying the importance of factors in market orientation. Much theoretical, conceptual, as well as empirical support for including market orientation in a research model was found. Hence, the inclusion of market orientation in the research model was theoretically defended. The study suggests that ornamental fish farmers must have a clear vision of how market orientation can deliver a value and competitive advantage. This is largely supported in this research. The findings demonstrate that a sophisticated use of key factors of market orientation may pay off in better firm performance. This finding is probably related to the increase in managers' expectations over the past few years. Managers now expect accurate delivery commitments, complete visibility into their orders and transactions, as well as proactive, personalized, and convenient support (Oracle 2005). The raised expectations have created a competitive pressure and challenges for ornamental fish farmers. Furthermore, the present study provides insight to the contingent relationships between the entrepreneurial dimensions and firm performance in a ornamental fish environment. These results have important implications for managers of small and medium scale enterprises. Managers of such firms should adopt a forward looking perspective as proactiveness leads to improved performance. However, they should be careful in engaging in novelty and experimentation resulting in new services or technological processes. Our findings also indicate that managers should be careful about making large and risky resource commitments.

\section{LIMITATIONS AND FUTURE RESEARCH}

The findings, conclusions, and implications of this research are bound by some important limitations. When interpreting parts of this study some caution is therefore needed. The study involves to some extent collection of retrospective data. As such, they may include more or less distorted views. This applies in particular to the perception-based variables. Since the data obtained in this study are not longitudinal, it precludes definitive causal claims. Due to its crosssectional nature, this study is for instance unable to identify any lags which may occur between reaching a higher level of organization performance. A major limitation of this study is that it depends on single respondents. Consequently, the current research relies on the judgement of owners to measure key factors affecting on market orientation. The reliance of self reported data from single respondents introduces the risk of common method variance. In order to obviate this risk, the procedure suggested by Wiklund and Sheperd (2003), and also used by other 
researchers with single respondents has been followed.

The findings in this study are furthermore derived only from a small and medium scale ornamental fish famers sample. The validity of generalization to other types of businesses, such as retiling or services, or other contexts, such as national markets, is as such limited. Based on the research work reported in this thesis, several suggestions for future research can be made. While some of the suggestions are consequences of the research findings reported in this study, such as the need for further testing of the nomological validity of the scale in new samples and contexts, others act more as an extension of the research conducted.

\section{REFERENCES}

Aldrich, H. E. (1990) Organizations and Environments, NJ, Prentice-Hall, Inc.

Antoncic, B. and Hisrich, R.D. (2003) Clarifying the Intrapreneurship Concept. Journal of Small Business and Enterprise Development, 10 (1), 7 -24 .

Desphande, R., Farley, J.U. and Webster, F.E. (1993) Corporate Culture, Customer Orientation, and Innovativeness in Japanese Firms: A Quadrad Analysis. Journal of Marketing, 57 (1), 23-37.

Desphande, R. and Farley, J. (1999) Executive Insights: Corporate Culture and Market Orientation: Comparing Indian and Japanese Firms. Journal of
International Marketing, 7 (4), 111 127.

Dess, G.G. and Robinson, R.B. (1984) Measuring Organizational Performance in the Absence of Objective Measures: The Case of the Privately-held Firm and Conglomerate Business Unit. Strategic Management Journal, 5 (3), $265-273$.

Dibbern, J., Goles, T., Hirschheim, R. and Jayatilaka, B. (2004) Information Systems Outsourcing: A Survey and Analysis of the Literature. ACM SIGMIS Database.

Douglas, S.P. and Craig, C.S. (1983) International Marketing Research. Englewood Cliffs, NJ: Prentice-Hall.

Drucker, P. (1989) What Business can Learn from Non-Profits. Harvard Business Review, 67 (4), 88-94.

Kara, A., Spillan, J.E. and DeShields, O.W. (2005) The Effect of a Market Orientation on Business Performance: A Study of Small-Sized Service Retailers Using MARKOR Scale. Journal of Small Business Management, 43 (2), 105-118.

Kholi, A.K. and Jaworski, B.J. (1990) Market Orientation: the Construct, Research Propositions, and Managerial Implications. Journal of Marketing, 54 (2), 1-18.

Kotler, P. and Amstrong, G. (2006) Principles of Marketing. $11^{\text {th }}$ edition, New Jersey: Prentice-Hall. 
Narver, J.C. and Slater, S.F. (1990): The Effect of Market Orientation on Business Profitability. Journal of Marketing. 54(4), 20 - 35.

Narver, J.C.; Slater, S.F.and MacLachian,D.L. (2000): Total market orientation, business performance, and innovation. Working Paper. Report no 00-116. Cambridge: Marketing Science Institute.

Peterson, R.T. (1989) Small Business Adoption of the Marketing Concept Vs. Other Business Strategies. Journal of Small Business management, 27 (1), 38-46.

Robinson, B.E. (1998) The Workaholic Family: A Clinical Perspective. The American Journal of Family Therapy, $26,65-75$.

Ruekert, R.W. (1992) Developing a Market Orientation: An Organizational Strategy Perspective. International Journal of Research in Marketing, 93 (3), 225-246.

Slater, S.F. and Narver, J.C. (1994): Does competitive environment moderate the market orientation - performance relationship? Journal of marketing. 58(1), 46-55.
Slater, S.F. and Narver, J. (2000): The positive effect of a market orientation on business profitability: a balanced replication. Journal of Business Research.48(1), 69-73.

Vesper, K.H. (1990) New Venture Strategies. University of Illinois Press; Washington.

Webster , F.E. Jr. (1994a): Defining the new marketing concept (part 1). Marketing Management.2(4), 22-32.

Westhead, P., Wright, M. and Ucbasaran, D. (2001) The Internationalization of New and Small Firms: A ResourceBased View.

Wrenn, B. (1997): The market orientation construct: measurement and scaling issues. Journal of Marketing Theory and Practice. 5(3), 31-54.

Zahra, S.A. and Covin, J.G. (1995): Contextual influences on the corporate entrepreneurship performance relationship : a longitudinal analysis. 